\title{
LOS MONSTRUOS MARINOS EN LA EDAD MODERNA: LA PERSISTENCIA DE UN MITO
}

\author{
Arturo Morgado García \\ Universidad de Cádiz
}

\section{RESUMEN}

Se parte de una visión del fenómeno de los monstruos a lo largo de la historia, para centrarnos más concretamente en el estudio de los monstruos marinos durante la Antigüedad, la Edad Media y los tiempos modernos, siendo una obra fundamental al respecto la del sueco Olao Magno. Muchos de sus monstruos serán recogidos por los zoólogos y los teratólogos de los siglos XVI y XVII, como Conrad Gessner y Ambroise Paré. Hay monstruos claramente imaginarios que no responden a ningún animal real, como el pez monje y el pez obispo, que encontraremos en bastantes autores de la época. Finalmente, se describe el último monstruo creado en la Modernidad: el kraken.

Palabras clave: mar, mitos, leyendas, monstruos, teratología.

\section{ABSTRACT}

First, we give a general view about the "monster" during the course of the history. After, we talk about the sea monsters during the Antiquity, the Middle Ages and the Modern Times. The work of the Swedish writer Olao Magno is very important, and his book was very readed by other zoologists and terathologists such Ambroise Paré and Conrad Gessner. We cand find too imaginary monsters, such "fish monk", and "fish bishop", described by too many writers. Finally, we talk about the last monster created during the Modern Times: the kraken.

Key words: sea, miths, legends, monsters, terathology.

Un monstruo, desde el punto de vista morfológico, es todo aquel que difiere notablemente de los individuos de su especie, una criatura fantástica, un ser contra natura, y con singularidades extraordinarias. Como diría Ambroise Paré al respecto, "Monstres sont choses qui apparoissent outre le cours de Nature (et sont le plus souvent signes de quelque malheur à advenir) comme un enfant qui naist avec un seul bras, un autre qui aura deux testes, et autres membres outre l'ordinaire. Prodiges, ce sont 
choses qui viennent du tout contre Nature, comme une femme qui enfantera un serpent, ou un chien, ou autre chose du tout contre Nature"1.

Lo cierto es que el poder de fascinación que tienen los monstruos es innegable. La Baja Edad Media ha sido, probablemente, el período histórico más receptivo ante el fenómeno monstruoso, que se presenta como algo objetivo y real, y de cuya existencia no cabe la menor duda ${ }^{2}$. Pero el tratamiento dado al fenómeno monstruoso no fue ni mucho menos unívoco. Una tendencia pretendía dar un cierto rigor científico al mismo, línea iniciada con Aristóteles y continuada en la Edad Media con Alberto Magno. Una segunda vertiente, muy presente en el mundo clásico y medieval, tuvo un marcado carácter cosmográfico y antropológico, volcándose en la descripción de las diferentes razas de hombres monstruosos que viven en determinadas zonas de Asia o Africa, destacando los ejemplos proporcionados por Heródoto, Plinio, Eliano y Solino, e intermediarios como San Isidoro contribuyeron a la transmisión de este saber durante la Edad Media ${ }^{3}$.

Finalmente, una última corriente pretende presentar al monstruo como un portento o un signo divino, lo que ya está presente en la obra de Cicerón, y lo continuarían San Agustín y San Isidoro. Para el primero, según muestra en su tratado Sobre la adivinación, ostentar, anunciar, mostrar o predecir, son vocablos que proceden directamente de anuncio, portento, monstruo o prodigio ${ }^{4}$. En la misma línea, San Agustín, en La ciudad de Dios, nos revelará cómo "portentos, ostentos, monstruos y prodigios... anuncian (portendere), manifiestan (ostendere), muestran (monstrare) y predicen (praedicare) algo futuro...la aparición de determinados portentos parece querer señalar hechos que van a acontecer, pues en ocasiones Dios quiere indicarnos lo que va a suceder a través de determinados perjuicios de los que nacen". Casi idénticas son las palabras de San Isidoro de Sevilla:

"Varrón dice que portentos son las cosas que parecen nacer en contra de la ley de la naturaleza. En realidad, no acontecen contra la naturaleza, puesto que suceden por voluntad divina, y voluntad del Creador es la naturaleza de todo lo creado...En consecuencia, el portento no se realiza en contra de la naturaleza, sino en contra de la naturaleza conocida. Y se conocen con el nombre de portentos, ostentos, monstruos y prodigios, porque anuncian (portendere), manifiestan (ostendere), muestran (monstrare) y predicen (praedicare)... Por su parte monstra deriva su nombre de monitus, porque se muestran para indicar algo, o porque muestran al punto qué significado tiene una cosa...La aparición de determinados portentos parece querer señalar hechos que van a acontecer, pues en ocasiones Dios quiere indicarnos lo que va a suceder a través de determinados perjuicios de los que nacen ".

A medida que nos vamos acercando a la Edad Moderna, los nacimientos monstruosos ${ }^{7}$ van adquiriendo connotaciones apocalípticas, presagiando la reforma del mundo, el destierro de la maldad y la reivindicación de la voluntad de Dios, siendo el alemán Sebastián Brandt (1457-1521) el más temprano y fecundo cultivador de la exégesis de lo prodigioso, con una marcada orientación política, naciendo la moda de la interpretación de lo monstruoso como un testimonio de la voluntad divina, ya sea en su condición de avisos, castigos o aprobaciones ${ }^{8}$. La publicación de los libros de prodigios empieza a ser especialmente notable en el siglo XVI e inicios del XVII, siendo uno de los más destacados el Prodigiorum liber del autor latino Julius Obsequens, completado por Conrad Lycosthenes en Prodigiorum ac ostentorum chronicon (Basilea, 1557) y estos tratados serán asimilados muy pronto por la tradición

\footnotetext{
PARE, Ambroise, Les CEuvres d'Ambroise Paré, conseiller et premier chirurgien du roy, divisées en vingt huict livres avec les figures \& portraicts, tant de l'anatomie, que des instruments de chirurgie, \& de plusieurs monstres, Revuës \& augmentées par l'autheur, quatrième édition, Paris, Gabriel Buon, 1585. In-fol, p. MXX. El libro XXV de esta obra es el dedicado a "Monstres et prodiges", y, para el tema de los monstruos marinos, interesa el capítulo XXXIV (pp. MLXVIss).

SALAMANCA BALLESTEROS, Alberto, Monstruos, ostentos y hermafroditas, Granada, 2007, p. 16.

LEWIS, C.S., La imagen del mundo, Barcelona, Península, 1997, pp. 117-118.

4 CICERON, Marco Tulio, "Sobre la adivinación", I, 42, Sobre la adivinación. Sobre el destino. Timeo, edición de Angel Escobar, Madrid, Gredos, 1999, pp. 122-123.

GARCIA HARRAN, Julio, "Las relaciones de monstruos en el contexto de la teratología ilustrada de la Edad Moderna", La fiesta. Actas del II Seminario de Relaciones de Sucesos, La Coruña, Sociedad de Cultura Valle Inclán, 1999, pp. 137-139.

6 SEVILLA, Isidoro de, Etimologías. Edición bilingue, XI, 3, 1-4, Madrid, BAC, 1982 traducción de José Oroz Reta y Manuel A. Marcos Casquero, p. 48.

La obra fundamental al respecto, WILSON, Dudley, Signs and portents. Monstrous births from the Middle Ages to the Enlightenment, Londres/Nueva York, Routledge, 1993. También, PARK, Katharine, y DASTON, L., "Unnatural conceptions: the study of monsters in sixteenth and seventeenth-century France and England", Past and Present, 92, 1981.

8 GARCIA HARRAN, Julio, op. cit., pp. 138-139.
} 
popular a través de la literatura de prodigios destacando las Histories prodigieuses (París, 1560) de Pierre Boaistuau, traducido parcialmente al español en Andrea Pescioni, Historias prodigiosas y maravillosas de diversos sucesos acaecidos en el mundo (Medina del Campo, 1586), destacando en España las obras de Torquemada (Jardin de flores curiosas), Pedro Mexia (Silva de varia lección) o Juan Eusebio Nieremberg (Curiosa y oculta filosofía $)^{9}$, pasando en muchas ocasiones estas apariciones monstruosas a las relaciones de sucesos, algunas de ellas recopiladas por Ettinghausen ${ }^{10}$. Esta interpretación sobrenatural de lo monstruoso, sin embargo, se va abandonando a lo largo del siglo XVII, y Albrecht von Haller (17081777) en De monstris (1768), posiblemente el primer tratado de teratología con un aire científico, señala cómo "desembaracémonos para comenzar de todos los monstruos, numerosos oráculos, cuya confianza no es digna, en los cuales a menudo no se encuentra nada verdaderamente monstruoso excepto la consecuente corrupción, o bien alguna deformidad, exagerada en historias maravillosas, en ocasiones completamente fraudulentas" 11 .

El origen de los monstruos fue una cuestión bastante debatida. Era muy frecuente en la ciencia medieval la creencia de que el monstruo era el producto de una actividad sexual anormal o desviada, señalando Torquemada en su Jardín de flores curiosas cómo "en estas cosas parece la naturaleza haberse mostrado tibia en el engendrar y por ventura el defecto estuvo en el sujeto de la mujer o en la simiente genital del padre, que con su imperfección no bastó a engendrar criatura más perfecta... pero lo más cierto es que se engendran de la superfluidad de los humores corrompidos que están en el cuerpo de una mujer" 12 . Ambroise Paré, en su tratado clásico al respecto, proporciona una batería de causas en las cuales se mezclan las religiosas, las mágicas, y las propiamente médicas: "La premiere est la gloire de Dieu. La seconde, son ire. La troisiéme, la trop grande quantité de semence. La quatriéme, la trop petite quantité. La cinquiéme, l'imagination. La sixiéme, l'angustie ou petitesse de la matrice. La septiéme, l'assiette indecente de la mere, comme, estant grosse, s'est tenue trop longuement assise les cuisses croisées, ou serrées contre le ventre. La huitiéme, par cheute, ou coups donnés contre le ventre de la mere estant grosse d'enfant. La neufiéme, par maladies hereditaires, ou accidentales. La dixiéme, par pourriture ou corruption de la semence. L'onziéme, par mixtion, ou meslange de semence. La douziéme, par l'artifice des meschans belistres de l'ostiere. La treiziéme, par les Demons ou Diables"13. Idéntico abigarramiento observamos en Fuentelapeña, el cual, tras remitirse a la autoridad aristotélica, nos hablará de causas tales "defecto, sobra, confusión, o corrupción o cualidades de semen, descomposición del útero o angustia de la matriz, deformidad de el principio, cópula ilegítima de diversas especies, la cópula en tiempo de menstruo, o fuera del modo ordinario, demasiada lujuria, la imaginación de los padres y tal vez la fuerza de los astros", si bien llama la atención el relativamente escaso papel jugado por los factores de carácter sobrenatural, aunque ello no le impida citar como fuente de monstruos "el concúbito de las mujeres con el demonio"14.

Con el tiempo el monstruo se convertiría en un fenómeno y en una curiosidad a exhibir, y el lugar predilecto para ello serán las cámaras de las maravillas (wunderkammer) ${ }^{15}$, cuyo precedente hay que buscarlo en los tesoros eclesiásticos de la Edad Media en los que prevalecía el concepto agustino de curiositas. Esta emoción tenía un marcado componente religioso, por cuanto Dios había creado el mundo y todo lo que contenía, y la divinidad demostraba su inmenso poder poblando el mundo de objetos tan notables, y a fin de que los hombres no se saturasen de demasiadas experiencias de este tipo, Dios utilizaba estos seres más como ornamentos que como la materia cotidiana de la creación. Vincent de Beauvais en El espejo de Natura (siglo XIII), refiriéndose a los monstruos marinos, señalaba cómo "han sido creados por Dios omnipotente para la admiración del mundo, nos resultan dignos de

\footnotetext{
NIEREMBERG, Juan Eusebio, Curiosa y oculta filosofía, Madrid, Imprenta de María Fernández, 1649.

10 ETTINGHAUSEN, Henry(ed.), Noticias del siglo XVII, relaciones españolas de sucesos naturales y sobrenaturales, Barcelona, Pulvill Libros, 1995.

11 SALAMANCA BALLESTEROS, Alberto, op. cit., p. 197

12 TORQUEMADA, Antonio de, Jardín de flores curiosas, edición de Giovanni Allegra, Madrid, Castalia, 1982, pp. 121-122.

13 PARE, Ambroise, op. cit., p. MXX.

14 FUENTELAPEÑA, Fray Antonio de, El Ente dilucidado. Discurso único novísimo que muestra hay en naturaleza animales irracionales invisibles y quales sean, Madrid, Imprenta Real, 1676, pp. 49ss.

15 El trabajo clásico al respecto, SCHLOSSER, Julius von, Las cámaras artísticas y maravillosas del Renacimiento Tardío, Madrid, Akal, 1988.
} 
encomio tan sólo porque aparecen con muy poca frecuencia ante los ojos de los hombres", por lo que, al contemplar seres como las ballenas o los delfines, el cristiano podía adquirir un sentido más adecuado de la grandeza divina ${ }^{16}$. Idea que seguirá persistiendo en el siglo XVII: Fray Antonio de Fuentelapeña nos dirá "aunque todas las criaturas, y obras de las soberanas manos nos sean motivo de conocer, alabar y venerar a N. Dios, mucho más lo son las extraordinarias que las comunes y tanto más, cuanto por menos practicadas (siendo la novedad estímulo gustoso del conocimiento) nos pica la atención para rastrear el Autor Soberano, cuando las comunes, por ordinarias, no deben a nuestra curiosidad la menor reflexión" ${ }^{17}$. Al fin y al cabo, no podemos olvidar, según mostrara Descartes, la importancia de la admiración por ser el primer paso en el proceso del aprendizaje, y tan sólo los necios y los estúpidos carecían de una inclinación natural hacia ella ${ }^{18}$. Pero las cámaras de las maravillas responden también al modelo baconiano de ciencia, dominado no sólo por la curiosidad, sino también por el deseo de coleccionar, y este deseo de clasificar y analizar permitirá el surgimiento de la moderna teratología, destacando de este modo los monstruos por su aspecto curioso e inusual ${ }^{19}$.

El mar constituía un ámbito privilegiado para que se desenvolviera en su seno la vida de monstruos de toda clase y condición, habida cuenta del fuerte temor que suscitaba el mismo: vientos, olas, tempestades...todo se conjuraba para que navegar fuese una experiencia llena de peligros e incertidumbres ${ }^{20}$. El mar siempre estará, además, asociado a la disolución de límites y a la locura: tal como señala Michel Foucault, "Dans l'imagination occidentale, la raison a longtemps appartenu à la terre ferme. Île ou continent, ele repousse l'eau avec un entêtement massif: elle ne lui concède que son sable. La déraison, elle, a été aquatique depuis le fond des temps et jusqu'à une date assez rapproché. Et plus précisement océanique: espace infini, incertain, figures mouvantes, aussitôt effacés, ne laissant derrière elles qu'un sans chemin"21. Y, por supuesto, sus moradores contribuían a aumentar estos sentimientos. Es cierto que en el mundo clásico Aristóteles intentó establecer los fundamentos de una zoología científica, pero sus continuadores abandonaron por completo estos parámetros ("frente a Aristóteles, tanto el enciclopédico Plinio como el curioso Eliano son epígonos de una ciencia a la que agregan detalles pintorescos y sobre la que coleccionan nuevos datos. Pero no están guiados...por ese afán de construir una ciencia que se entronca con una explicación científica y filosófíca del cosmos...sino por un empeño erudito de mostrar las maravillas y curiosidades de una realidad tremendamente abigarrada $y$ sorprendente" $)^{22}$, y no tuvieron empacho en cubrir el mundo de bestias extrañas y sorprendentes. Sin embargo, el ámbito marino se encuentra relativamente despoblado de criaturas monstruosas. El mundo mediterráneo era sobradamente conocido y pocas sorpresas faunísticas podía deparar: al fin y al cabo, como dijera a inicios del siglo XV Pierre D' Ailly, el Mare Nostrum “no tiene peces de gran tamaño, excepto focas, atunes y delfines" ${ }^{\prime 2}$. De hecho, las escasas criaturas monstruosas a las que se hace referencia las encontraremos fundamentalmente en el océano Indico, espacio marino poco conocido para nuestros autores y que, por consiguiente, dejaba un mayor campo abierto a las elucubraciones fantásticas...sin olvidar tampoco el hecho de que las regiones orientales constituían, ya desde los tiempos de Heródoto, la tierra de las maravillas por excelencia ${ }^{24}$.

Los autores que nos interesan son, básicamente, Plinio el Viejo, Claudio Eliano y San Isidoro de Sevilla. La obra de Solino, que se considera un precedente indispensable de los bestiarios medievales,

16 PARK, Katharine, "Una historia de la admiración y del prodigio", Monstruos y seres imaginarios en la Biblioteca Nacional, Madrid, Algete, 2000, pp. 80ss. Vid. sobre todo, PARK, Katharine, y DASTON, L., Wonders and the Order of Nature, Nueva York, Zone Books, 1998.

17 FUENTELAPEÑA, Fray Antonio de, op. cit. c, "Prólogo".

18 PARK, Katharine, op. cit.

19 WILSON, Dudley, op. cit., p. 74

20 DELUMEAU, Jean, El miedo en Occidente (siglos XIV-XVIII). Una ciudad sitiada, Madrid, Taurus, 1989, pp. 53ss.

21 FOUCAULT, Michel: "L'eau et la folie" en FOUCAULT, M.: Dits et Écrits 1954-1958, tome I, Paris, Gallimard, 1994, pp. 268272, p. 268 (edición original de este artículo, publicado en Médecine et Hygiène, 613, 23 oct. 1963, pp. 901-906). Agradecemos a Francisco Vázquez García el habernos proporcionado esta referencia.

22 ARISTOTELES, Investigación sobre los animales, introducción de Carlos García Gual, Madrid, Gredos, 1992 , p. 31.

23 D' AILLY, Pedro, Imago mundi, capítulo quincuagésimo. El mar Mediterráneo, edición de Antonio Ramírez de Verger, Madrid, Testimonio Compañía editorial, 1990 (1410), p. 177.

24 El trabajo clásico al respecto, WITTKOWER, Rudolf, "Marvels of the East: a study in the history of monsters", Journal of the Warburg and Courtauld Institutes, 5, 1942, pp. 159-197. 
no contiene referencias a monstruos marinos, aunque sí las inevitables alusiones a las razas monstruosas que pueblan la India. Elemento común a todos ellos será, ante todo, la localización de los monstruos marinos allende el Mediterráneo: así, Plinio el Viejo nos muestra cómo "hay en el mar de la India muchos y muy grandes animales entre los cuales son las ballenas de tamaño de cuatro higüeros y los pristes (pez espada) de 200 codos. Y no es maravilla, pues son las langostas alli de cuatro codos, y las anguilas en el río Ganges de 30 pies. Vense todas estas bestias por la mayor parte en el mar por el tiempo del Solsticio... hay una medio ínsula grande en el mar Bermejo, llamada Cadara (Qatar). Oponiéndose ésta al mar, hace un grande seno, el cual navegó a remo el rey Ptolomeo en espacio de 12 días con sus noches, porque no corre en él viento alguno. En este lugar, por su grande calma, crecen tan extrañamente estas bestias que vienen a término de no se poder rodear" 25 . También, para Claudio Eliano, el océano Indico es el hábitat por excelencia de tan extrañas criaturas: "parece que en el Océano Indico hay monstruos marinos de un tamaño cinco veces mayor que el del más grande elefante. Una sola costilla del monstruo mide unos veinte codos, tiene una quijada de quince y la aleta de cada branquia es de siete codos de anchura...dicen que el mar que ciñe a la isla (Trapobana) cría una muchedumbre incontable de peces y monstruos, y dicen, además, que éstos tienen cabezas de leones, leopardos, lobos y corderos, y, lo que es más prodigioso, hay monstruos que tienen formas de sátiros con cabezas de mujeres provistas de espinas en vez de cabellos. Se dice que hay otros que tienen extrañas formas, imposibles de ser representadas por hombres duchos en pintura y en mezclar cuerpos distintos para la ejecución de algo prodigioso de ver...tienen colas larguísimas y en espiral, mientras que sus pies son a manera de garras o aletas, y me he enterado de que son anfibios, y de que de noche pastan en los campos porque comen hierba...y luego, cuando muere la noche y viene el crepúsculo, desaparecen sumergiéndose en el mar al rayar el alba"26. No olvidemos el hecho de que el mar es un lugar privilegiado para que estos seres puedan desarrollar su existencia, por cuanto "causa manifiesta es de ello la muchedumbre del agua...en el mar, tan anchamente tendido y que con crecimiento manso y fértil recibe del cielo fuerza de engendrar, produciendo siempre naturaleza, se hallan de muchas cosas, no sólo ordinarias, mas también monstruosas, mezcladas y revueltas las simientes y principios entre sí de diversas maneras, ya con el viento, ya con las olas" ${ }^{27}$.

¿Y cuáles son estas bestias? Ciertamente, no son demasiadas. Para Plinio destacan ante todo la ballena y el physeter: "los mayores animales que se hallan en el mar de la India son pristes y ballenas, en el océano Gálico, el physeter, el cual se levanta a manera de una muy grande columna y estando más alto que las velas, rebosa un diluvio de aguas" ${ }^{\prime 2}$, aludiendo más adelante al becerro marino y al pez carnero ${ }^{29}$. Claudio Eliano, por su parte, nos habla de los trochoi, "monstruos marinos de excesiva corpulencia y de tamaño prodigioso nadan en medio de los océanos y, a veces, son fulminados por el rayo. Además de éstos, hay otros semejantes que llegan hasta la costa y que se llaman trochoi... dicen que no son valientes, aunque lucen cresta y espinas enormemente largas, de modo que muchas veces son visibles por encima del agua. Y en cuanto oyen el golpeteo de los remos, se revuelven, se contraen y se sumergen a la mayor profundidad posible. De esta propiedad se deriva su nombre. Luego se desenrollan nuevamente y con un movimiento en espiral ascienden a la superficie" ${ }^{30}$, refiriéndose también al carnero marino (en opinión de García Gual, debe tratarse de la orca gladiator) ${ }^{31}$.

Isidoro de Sevilla, por su parte, en el libro XII de sus Etimologías, aborda el tema de los animales, mostrándonos algunos seres propios de las regiones marinas, aunque por su carácter monstruoso tan sólo cabe referirse a las ballenas, "animales de unas proporciones gigantescas, y se les llama así porque arrojan y expelen agua, provocan unos remolinos mucho más profundos que todos los otros animales marinos. En griego, ballein significa arrojar. Se les denomina también cetáceos (cete) del griego to ketos

\footnotetext{
25 PLINIO SEGUNDO, Cayo, Historia natural, traducción de Francisco Hernández y Jerónimo de Huerta (1624), Universidad Nacional de México, Visor Libros, 1999, Libro noveno "De los animales del agua", cap. III. "De las bestias del mar Indico" (IX, 3), p. 433 .

26 ELIANO, Claudio, Historia de los animales, libros IX-XVII, Madrid, Biblioteca Clásica Gredos, 1984, edición de Carlos García Gual, lib. XVI, 12 y 18 , pp. 254 y 259.

27 PLINIO SEGUNDO, Cayo, op. cit., lib. IX, cap. II, "Porqué haya en el mar tan grandes pescados", p. 431.

28 PLINIO SEGUNDO, Cayo, op. cit., lib. IX, cap. IV, "Qué animales sean mayores en diversas partes del océano”, p. 433.

9LINIO SEGUNDO, Cayo, op. cit., lib. IX, cap. XIII y XLIV, pp. 445 y 474

ELIANO, Claudio, op. cit., lib. XIII, 20, p. 173.

1 ELIANO, Claudio, op. cit., XV, 2, pp. 219-220.
} 
y ta kete, es decir, a causa de su magnitud. Son una clase de bestias de enormes proporciones y dotadas de un cuerpo semejante a una montaña; tal fue el cetáceo que se tragó a Jonás y cuyas entrañas eran tan gigantescas que tenía la impresión de haber llegado al infierno" "32. A juzgar por la escasez de estos testimonios, el mundo clásico no debió constituir, en modo alguno, la fuente de la que bebieron muchos de los posteriores relatos de monstruos marinos que hallamos a lo largo de la Modernidad.

Tampoco en el mundo medieval son demasiado numerosas las referencias, a pesar de que a lo largo de este período primara poderosamente una imagen fantástica y mítica de la Naturaleza, muy bien reflejada en los diversos bestiarios que se fueron recopilando a lo largo de esta época. Este género literario, muy popular durante este período, describía animales, plantas, e incluso rocas, y la historia natural y la descripción de cada animal era acompañada con una lección moralizante, reflejando la creencia de que el mundo era literalmente una creación divina, y que, por consiguiente, cada ser vivo tenía su función en el mismo. Fueron especialmente populares en Francia e Inglaterra durante el siglo XII, y solían recopilar de modo acrítico textos anteriores. El primer bestiario conocido era un antiguo volumen griego del siglo II conocido como el Physiologus, que reunía información procedente de Aristóteles, Heródoto, Plinio el Viejo, Cayo Julio Solino y Claudio Eliano. Pero este género no tenía un propósito lúdico, antes al contrario, su propósito era la edificación del cristiano, proporcionando numeroso material tanto para la predicación como para la interpretación de las esculturas que se encontraban por doquier en las iglesias románicas. El Speculum naturae de Vincent de Beauvais (siglo XIII) supondrá la culminación de este género literario (para los animales marinos interesan particularmente los libros XVI y XVII), que sería herido de muerte con la obra De Animalibus de San Alberto Magno, que defenderá una aproximación más científica al estudio de la Naturaleza, y que será, con mucho, la mejor obra dedicada al tema escrita en la época medieval, si bien las fábulas contenidas en los bestiarios seguirán estando muy presentes en la cultura renacentista. Naturalmente, la inclusión de animales marinos, aunque muy parca dado el carácter esencialmente agrario de la civilización medieval, contiene algunos seres monstruosos, y, en este sentido, la ballena es el monstruo por excelencia, a la vez signo divino y un animal de proporciones gigantescas, siendo el equivalente marino al lobo, y, al igual que éste, provista de una poderosa dentadura ${ }^{33}$. Entre algunos representantes de este género ${ }^{34}$ podríamos citar el Bestiario de Aberdeen del siglo XII (donde se nos habla de la ballena y del puerco marino ${ }^{35}$, el Bestiario Harley (con ilustraciones de la ballena y la sirena) de la Bristish Library ${ }^{36}$ y el Bestiario Ashmole (en el que encontramos nuevamente a ambas) conservado en la Bodleian Library de la universidad de Oxford $^{37}$, estos últimos del siglo XIII.

La otra vertiente a través de la cual el mundo medieval se aproximó a los seres monstruosos viene representada por los libros de viajes, que daban cabida en su seno a numerosos elementos míticos, fabulosos y fantásticos, tanto más abundantes cuanto más lejos nos situamos del Occidente cristiano. Los primeros viajes de los europeos al Extremo Oriente en el siglo XIII iniciaron esta corriente, si bien en $E l$ Libro de las Maravillas de Marco Polo apenas se encuentran referencias a monstruos marinos: alguna cita, nuevamente, sobre la pesca de la ballena, con el objetivo de extraer el ámbar, en torno a la isla de Socotora, frente a la costa arábiga, aunque desprovista en el texto de elementos fantásticos ${ }^{38}$. Tampoco ofrece interés la obra de uno de los mayores (y más amenos) falsarios de todos los tiempos, John de Mandeville $^{39}$ en lo que a nuestro tema se refiere, ya que, si bien es cierto que puebla todo el Oriente de seres humanos fabulosos, no encontramos referencias a monstruos marinos, que estarán ausentes hasta las obras de los cosmógrafos del siglo XVI, que viven una época completamente diferente: ya se

32 SEVILLA, Isidoro de, Etimologías. Edición bilingue, II (libros XI-XX), trad. de José Oroz Reta y Manuel A. Marcos Casquero, Madrid, BAC, 1982. Lib. XII. "De animalibus", 6, "Sobre los peces" (XII, 6, 7-8, p. 95).

33 Numeroso material gráfico en la exposición "Bestiare du Moyen Age", en la web de la Bibliotheque Nationale de France ( http:// expositions.bnf.fr/bestiaire/index.htm). (17-10-2007).

${ }_{34}$ Una clasificación completa en "The Medieval bestiary" (http://bestiary.ca/). (17-10-2007). También, "Bestiaria latina" (http:// bestlatin.net/sources/medievalbestiaryca.htm). (17-10-2007).

35 http://www.abdn.ac.uk/bestiary/ (17-10-2007).

36 http://bestiary.ca/manuscripts/manu1010.htm (17-10-2007).

37 http://bestiary.ca/manuscripts/manu556.htm (17-10-2007).

38 MARCO POLO, Libro de las maravillas, CXCI, edición de Mauro Armiño, Madrid, Anaya, 1983, p. 421.

${ }^{39}$ MANDEVILLA, Juan de, Libro de las maravillas del mundo (Ms. Esc. M-III-7), edición de María Mercedes Rodríguez Temperley, Buenos Aires, Secrit, 2005. 
han iniciado la expansión ibérica y los grandes viajes ultramarinos, y la apertura del inmenso Océano Atlántico, antes casi completamente ignorado por los europeos, ofrecerá un terreno abonado para la descripción de fantásticas criaturas.

El ejemplo más delirante viene proporcionado por la Carta Marina de Escandinavia ${ }^{40}$ elaborada por Olao Magno (1490-1557) en 1539, dado la variedad de monstruosidades marinas incluidas en la misma, muchas de las cuales serán recogidas por los autores posteriores. Pero la obra que le consagraría como el auténtico creador de los monstruos marinos de los mares septentrionales sería su Historia de gentibus septentrionalibus ${ }^{41}$, una de las primeras que el Occidente europeo conoció sobre el mundo escandinavo, impresa en Roma en $1555^{42}$, y que conocería una formidable difusión al ser traducida al italiano (1565), alemán (1567), inglés (1658) y holandés (1665), con extractos publicados en Amberes (1558 y 1562), Paris (1561), Amsterdam (1586), Frankfort (1618) y Leyden (1652). El libro que nos interesa es, concretamente, el XXI, dedicado a "De piscibus monstrosis", y en el mismo aparecen numerosos seres que ya habíamos encontrado reflejados en la Carta marina.

¿Qué es lo que ofrece el autor sueco? Aparte de sus simples, pero llenas de encanto, ilustraciones, que servirán de inspiración a numerosos autores posteriores, Olao Magno es el responsable de trasladar el hábitat de los monstruos marinos del lejano Océano Indico a los mares del Atlántico norte. Ante todo, nos presenta los mares del Septentrión como un mundo lleno de peligros y amenazas: "se considera peligrosa la pesca en el océano Noruego por múltiples razones, dado que se lleva a cabo en alta mar en un trecho muy largo del litoral. Cuando surgen las impetuosas tempestades, los pescadores quedan rapidísimamente sumergidos por el oleaje, son dispersados por las enormes moles de hielos flotantes, se ven apartados a diversos lugares luchando con ballenas y monstruos, y, finalmente, ante la forma horrible y el contacto de determinados peces o monstruos hechos salir del abismo, sienten sus manos

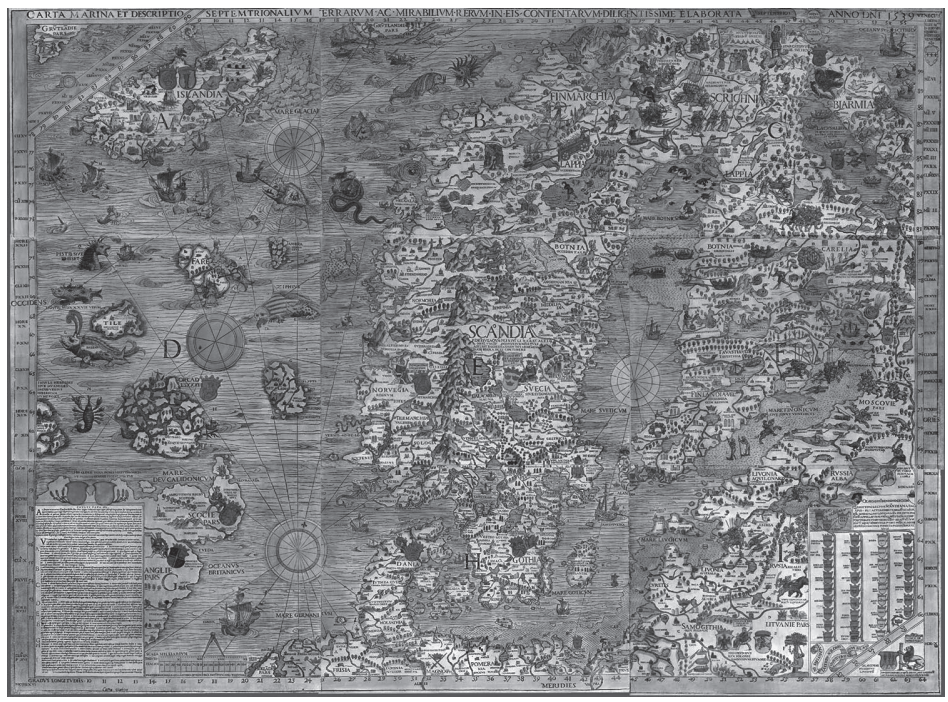

Olao Magno, Carta marina.

\footnotetext{
40 Edición digital en la James Ford Bell Library de la Universidad de Minnesota http://bell.lib.umn.edu/map/OLAUS/MAP/indexm. html (25-10-2007).

${ }_{41}$ Nuestras citas proceden de MAGNO, Olao, Historia de las gentes septentrionales, Madrid, Tecnos, 1989, edición de Daniel Terán Fierro, que utiliza el epítome latino publicado en Amberes en 1562. La edición de Roma de 1555, en la web de la Biblioteca Foral de Vizcaya.

42 GARCIA ARRANZ, José Julio, "Olao Magno y la difusión de noticias sobre fauna exótica del norte de Europa en el siglo XVI", PABA, Antonia, y RENALES, Gabriel Andrés, Encuentro de civilizaciones (1500-1750: informar, narrar, celebrar: actas del Tercer Coloquio Internacional sobre relaciones de sucesos, Alcalá de Henares, Universidad, 2003, pp. 171-184.
} 
enervadas y, si no los abandonan inmediatamente, pueden quedar ahogados en medio del excitado temporal...cada vez que son extraídos del mar peces monstruosos con rostro humano o de león y otros semejantes, se ha podido observar que siempre pronostican la discordia y las guerras en aquellas tierras" (cap. 1, "De la pesca peligrosa en el Océano noruego").

La panoplia monstruosa es muy amplia, pero destacan, normalmente, por su tamaño, su ferocidad, el peligro que representan para los marineros, y su fealdad nacida de su aspecto deforme, a la vez que en muchas ocasiones su presencia es anticipo de futuras calamidades. Es de destacar que Olao presenta a todas estas criaturas como seres reales y tangibles, sin que tengan ningún significado simbólico. Así, "hay peces monstruosos en las costas o en el mar de Noruega, de nombre inusitado (aunque se consideran del género de los cetáceos), que ya en su primer aspecto ponen de manifiesto su crueldad, e infunden horror a quienes los mira, produciendo espanto e incluso estupor si se prolonga su contemplación. Pues tienen formar horribles, cabezas cuadradas, punzantes por todas partes y rodeadas de cuernos agudos y largos...ojos desmesurados, de diez o doce codos de longitud, color muy negro: su contorno excede los ocho o diez codos....una sola de estas bestias vuelca con suma facilidad y sumerge muchas grandes naves" (cap. 5, "De los horribles monstruos de las costas de Noruega").

El físeter o príster, del género de los cetáceos, tiene un tamaño de doscientos codos, "se alza muy por encima de las antenas de las naves y, extrayendo el oleaje de agua contenido en unas fístulas sobre la cabeza, lo arroja de tal manera, que como una inundación de lluvia hunde muchas veces las naves más resistentes...posee también una boca grande y amplia...tiene en todo el cuerpo una piel espesa y negra, aletas largas en forma de pies anchos, y cola de dos puntas de quince y veinte pies de anchura, con la que estrecha violentamente las partes rodeadas de las naves" (cap. 6, "Del fiseter y su crueldad con los marineros"). Algunos cetáceos, por su parte, "tienen la abertura de la boca con dientes, y muy dilatada, es decir, con una prolongación de doce a catorce pies, y dientes de seis, ocho o doce pies. Los dientes caninos son más alargados que los demás, hacia abajo, como un cuerno, a la manera de los colmillos del jabalí o del elefante...dispone de ojos tan amplios que el contorno de cada uno admite a quince hombres sentados, incluso veinte o más según el tamaño de la bestia. Asimismo, encima de cada ojo tiene una especie de antena, en número de doscientas cincuenta, con una longitud de seis o siete pies" (cap. 8, "Del múltiple género de los cetáceos").

También nos hablará de la xifia, con una "cabeza espantosa, como un búho, la boca muy profunda, como un abismo inmenso, que aterroriza y pone en fuga a quienes le contemplan, ojos horribles, dorso en forma de cuña o elevado en forma de espada, hocico terminado en punto", el monocerote o unicornio marino, el sierra (cap. 10, "Del xifia, el monocerote y el sierra"), el rosmaro o morso noruego "del tamaño de un elefante...así llamados por la crueldad de sus mordiscos...tienen la cabeza bovina, la piel hirsuta y pelos que, con el grosor de pajas o cañas de trigo, se dispersan ampliamente...con los dientes se elevan a la cumbre de las rocas como si fuesen por escaleras" (cap. 19, "Del rosmaro o morso noruego"), el "swamfisck", "animal más glotón que todas las demás bestias marinas: apenas se sacia con las continuas presas, y se dice que no tiene un estómago diferente, se ahí que todo lo que come sea convertido en gordura", el "cahab", "que tiene patas pequeñas...aunque una de ellas es alargada, que utiliza en lugar de una mano para defender todos sus miembros y por medio de ella acerca el alimento a su boca y arranca las hierbas", el "cirkos", "que posee la piel del color del ladrillo, blanda, en parte negra, en parte rojiza, presenta dos fisuras en el pie, que dan origen a tres dedos" (cap. 25, "Del pez que los noruegos llaman "swamfisck" y de algunos otros monstruos marinos"), y, por supuesto, de la serpiente de mar, "de gigantesca mole, de doscientos y más pies de longitud, y veinte pies de grosor, que habita en rocas y cavernas, merodeando junto a las orillas del mar Bergense, la cual solamente sale de los antros en verano con el tiempo lúcido de la noche...devasta los navíos, irguiéndose hacia lo alto a modo de una columna atrapa a los hombres y los devora, y esto no suele acontecer sin un portentoso espectáculo referido a alguna alteración del reino" (cap. 27, "Del gran tamaño de la serpiente noruega y de otros"). En bastantes ocasiones, la iconografía de estos monstruos será una copia directa de la Carta marina, tal como se puede observar en los casos del fiseter, el rosmaro, el puerco monstruoso del mar Germánico, la serpiente marina, o la imagen de una ballena echando a pique un navío.

Es raro que Olao nos informe de un ejemplo concreto de estos portentos naturales, siendo una excepción al respecto el pez monstruoso encontrado en las costas noruegas en 1532, caracterizado 
por su descomunal tamaño (cap. 9, "Del monstruoso pez que se encontró en el litoral septentrional en el año 1532"), o el puerco monstruoso hallado en las costas del océano germánico en 1537, con "cabeza porcina, cuarta parte de la luna en el cogote, cuatro pies de dragón, dos ojos de uno y otro lado en los lomos, un tercero en el vientre inclinándose hacia el ombligo, y en las partes posteriores una cola bifurcada como un pez común" (cap. 18, "Del puerco monstruoso del Océano Germánico"). Lo cierto es que su obra ejerció una poderosísima influencia: buena muestra de ello son las continuas referencias que encontramos en el Jardín de Flores curiosas (1570) de Antonio de Torquemada, cuyo tratado sexto, "En que se dicen algunas cosas que hay en las tierras septentrionales" se basa en buena medida en la obra del autor escandinavo, de quien copia casi literalmente las referencias aparecidas a monstruos marinos ${ }^{43}$. La geografía septentrional como género historiográfico y folklórico acabaría adquiriendo una gran fortuna en España, culminando con la obra cervantina Los trabajos de Persiles y Segismunda ${ }^{44}$.

A partir de la publicación de las obras de Olao Magno, las referencias a monstruos marinos se hacen mucho más numerosas, siendo de destacar que, en muchas ocasiones, las ilustraciones son idénticas, como consecuencia de una cultura que en, el siglo XVI, es todavía fuertemente libresca ${ }^{45}$, y que sigue creyendo sobremanera en el principio de autoridad, por lo que no es de extrañar que tanto textos como imágenes se transmitan sin apenas variaciones. Tal como acertadamente señalaron Paul Delaunay y Jean Theodórides, "el valor documental de esta ilustración es muy desigual. Numerosos son los anónimos clichés passe-partout que por préstamo o plagio se transmiten de una obra a otra... muchos son además tendenciosos deformados por las tradiciones artísticas antiguas...Gesner la dota (a la ballena) de defensas múltiples y amenazadoras...las figuras de Rondelet aunque mediocres como las de Belon suelen ser exactas en los detalles mientras que las 99 planchas de Salviani aunque muy buenas desde el punto de vista estético se fijan sólo muy aproximadamente en espinas dientes etc. Mediocres pero generalmente concienzudas son las de Gesner"46.

Estas referencias las podemos encontrar, ante todo, en los cosmógrafos, comenzando por la obra de Sebastián Munster (1489-1552), traductor al latín en 1540 de la Geografía de Ptolomeo, y autor de la Cosmographiae universalis libri VI. Publicada originalmente en lengua alemana (Basilea, 1544), conocería sucesivas ediciones en latín, francés, italiano y checo, y fue una de los libros más leídos del siglo XVI, en parte gracias a sus excelentes ilustraciones. Munster reconoce su deuda con Olao Magno, al que cita entre las autoridades consultadas, y de la misma nos interesa especialmente su Tabula monstrorum marinorum incluida en el libro IV, tras hablar de la isla de Groenlandia ${ }^{47}$ (lo que nos muestra, nuevamente, la visión de los mares septentrionales como hábitat privilegiado de estas criaturas). En dicha tabla nos encontramos criaturas que han sido claramente extraídas de la obra del autor sueco, utilizando incluso sus mismas ilustraciones, tal como sucede con el fiseter, la serpiente marina, o el puerco del océano Germánico (cuya fecha de aparición, 1537, es la misma que nos da Olao Magno). Algo más comedido se muestra otro de los grandes cosmógrafos del siglo XVI, Abraham Ortelius (15271598), que en 1571 publicara en Amberes la primera edición del Theatrum orbis terrarum, aunque ello no le impedirá incluir en el mapa dedicado al Océano Pacífico en la edición de $1572^{48}$ la socorrida imagen de una ballena atacando un navío, aunque parece tratarse más de un elemento meramente decorativo.

\footnotetext{
43 TORQUEMADA, Antonio de, op. cit., pp. 471-477. Numerosas contribuciones sobre su obra en el Congreso Internacional Antonio de Torquemada y la literatura del Siglo de Oro celebrado en León-Astorga en el año 2003. Sobre su contenido teratológico, CASTILLO DURAN, Fernando del, Las vías de lo inverosímil en la literatura española del renacimiento: la teratología en el Jardin de flores curiosas de Antonio de Torquemada, Universidad Autónoma de Barcelona, 1998, microfichas.

44 ALLEGRA, Giovanni, “Antonio de Torquemada mitógrafo ingenuo y popular", RUGG, Evelyn, y GORDON, Alan M., Actas del Sexto Congreso Internacional de Hispanistas, 1980.

45 LEWIS, C.S., op. cit., pp. 13-14, 18

46 DELAUNAY, Paul, y THEODORIDES, Jean, "La zoología", TATON, Rene (dir)., Historia general de las ciencias, tomo 2. La ciencia moderna, Barcelona, destino, 1972, pp. 192-193.

47 MUNSTER, Sebastian, Cosmographiae universalis libri VI, Basilea, Henrichum Petri, 1552, pp. 850-853. Biblioteca Nacional de Portugal (http://purl.pt/13845) (30-10-2007).

48 ORTELIUS, Abraham, Theatrum orbis terrarum, Nuremnberg, Johann Koler, 1572, p. 196, disponible en versión digital en la Herzogin Anna Amalia Bibliothek de Weimar.
} 
No sucede lo mismo, sin embargo, con el mapa dedicado a Islandia en la edición de Amberes de 1595 , poblado de criaturas marinas que parecen haber sido extraídas de Olao Magno ${ }^{49}$.

Menos conocido es el monje franciscano André Thevet (1516-1592), que realizaría dos grandes viajes marítimos, uno al Mediterráneo oriental que le llevaría hasta Egipto y Palestina (1549-1554), y el segundo a Brasil (1555-1556). Desde 1560 sería cosmógrafo en la corte de los Valois, y revelará al lector una tierra poblada de criaturas singulares, extrañas, diferentes y desconocidas, pero insertas en un mundo natural lleno de similaridades y analogías con la flora, la fauna y, a veces, el hombre europeo ${ }^{50}$. La aportación más interesante de su Cosmographie Universelle (París, Guillaume Chaudiere, 1575) será una especie de unicornio de mar al que denomina vtelif y que ubica en las costas africanas, siendo copiada su iconografía por otros autores posteriores ${ }^{51}$.

La obra de Olao Magno influyó también poderosamente en algunos de los tratados de zoología escritos a lo largo del siglo XVI. Fueron precisamente los peces los primeros animales que atrajeron la atención, si hacemos exclusión de las aves, y la primera figura que nos interesa al respecto es la del erudito suizo Conrad Gessner (1516-1565) $)^{52}$, autor de una Historia animalium ${ }^{53}$ en la cual describe a los diferentes seres vivos empleando un criterio alfabético, aunque ello no impide que indique el género al cual pertenecen seguido de un calificativo, que será al final el criterio empleado por Linneo en el siglo XVIII. De cada uno de ellos nos muestra su denominación en diferentes lenguas, su hábitat, sus orígenes, su descripción anatómica, algunas de sus costumbres, su interés desde el punto de vista médico o alimenticio, y las ocasiones en que han sido citados por diferentes autores. Un interés añadido para la obra estriba en sus magníficas ilustraciones, algunas de ellas recopiladas en su Icones animalium ${ }^{54}$ aunque tal alarde erudito no impedirá que Gessner se deje influir por las historias relativas a seres monstruosos, y, en lo que se refiere concretamente a los monstruos marinos, heredará dos tradiciones : los seres antropomorfos procedentes del mundo clásico, a los que más adelante nos referiremos, y el bestiario aportado por Olao Magno. Los ejemplos que encontramos al respecto en la obra de nuestro suizo son bastante numerosos: la ballena monstruosa que amenaza con hundir a un navío ${ }^{55}$, el "apro cetaceo" 56 , el "ceto barbato" 57 , el "ceto capillato" 58 , la "hyaena cetacea", que no es más que el puerco marino descrito por el autor sueco ${ }^{59}$, el fiseter ${ }^{60}$, el rosmaro ${ }^{61}$, el "ceto britannico" 62 , o la gigantesca serpiente marina ${ }^{63}$....en las descripciones de todos ellos se alude siempre a la obra de Olao Magno, de quien se toman directamente las ilustraciones representadas en la Carta marina.

49 Mapa incluido en la exposición virtual "La mer: terreur et fascination" de la Bibliotheque Nationale de France (http://expositions. bnf.fr/lamer/grand/151.htm) (30-10-2007).

50 FERREIRA FURTADO, Junia, "Le merveilleux, le monstrueux et le singulier dans la cosmographie de la terre d' André Thevet", STOLS, Hedí, THOMAS, Werner, y VERBERCKMOES, Johan (eds.), Naturalia, Mirabilia et Monstrosa en los Imperios ibéricos, Leuven University Press, 2006.

${ }^{51}$ THEVET, André, Cosmographie universelle, París, Guillaume Chaudiere, 1575, p. 146. Edición digital en la Bibliotheque Nationale de France (http://gallica.bnf.fr/) (30-10-2007).

52 PYLE, C., "Conrad Gessner on the Speling of his Name", Archives of Natural History, 27, 2000, pp. 175-186. El trabajo clásico sobr elos ictioólogos del siglo XVI, GUDGER, E.W., "The five great naturalists of the XVIth century, Belon, Rondelet, Salviani, Gesner, and Aldrovandi: a chapter in the history of ictthyology", Isis, XII, 1934.

53 La obra se organiza en cuatro tomos: Quadrupedes vivipares (1551), Quadrupedes ovipares (1554), Avium natura (1555) y Piscium \& et aquatilium animantium natura (1558). El último ha sido consultado en edición digital en la biblioteca virtual de la Universidad Complutense de Madrid.

${ }^{54}$ Consultada la versión publicada en Zurich por el impresor Christoph Froshover en 1560, disponible en edición digital en la biblioteca virtual de la Universidad de Estrasburgo . http://imgbase-scd-ulp.u-strasbg.fr/displayimage.php?album=287\&pos=1 (3010-2007).

55 GESSNER, Conrad, Historie animalium, Liber IIII qui est de Piscium et Aquatilium animantium natura, Zurich, Christoph Froshover, p. 138.

56 GESSNER, Conrad, Historiae animalium, p. 246, e Icones animalium aquatilium in Mari et dulcibus aquis, Zurich, Christoph Froshover, 1560 , p. 369.

57 GESSNER, Conrad, Historiae animalium, p.246.

58 GESSNER, Conrad, Historiae animalium, p. 247, e Icones animalium, p. 180

59 GESSNER, Conrad, Historiae animalium, p. 247, e Icones animalium, p. 180.

60 GESSNER, Conrad, Historiae animalium, p. 248.

${ }_{61}$ GESSNER, Conrad, Historiae animalium, p. 249, e Icones animalium, p. 368

62 GESSNER, Conrad, Historiae animalium, p. 251.

63 GESSNER, Conrad, Historiae animalium, p. 1040, e Icones animalium, p. 93. 


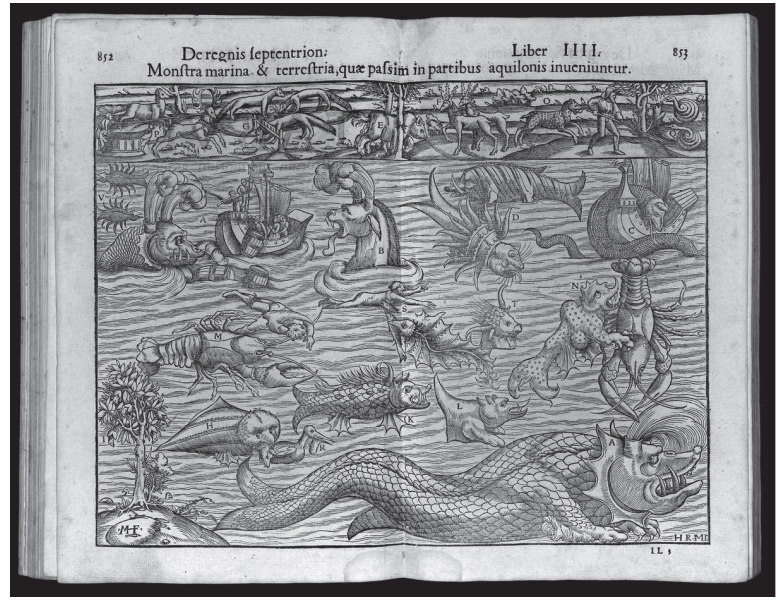

Sebastián Munster, Tabula monstrorum marinarum

Más comedidos se muestran otros ictiólogos del siglo XVI. El primero de ellos, el francés Pierre Belon (1517-1564) ${ }^{64}$, realizó uno de los primeros viajes de la historia con fines estrictamente naturalistas, que le llevaría a recorrer entre 1546 y 1549 las tierras de Grecia, Palestina, Egipto, y la península arábiga. Incluirá en su obra todas las criaturas marinas, incluso mamíferos como el hipopótamo o la ballena, pero observamos un intento de clasificación científica, al distinguir entre ovíparos y vivíparos, o esqueleto óseo o cartilaginoso, siendo mínimos los elementos fantásticos presentes. Por lo que se refiere a su compatriota Guillaume Rondelet (1507-1566) ${ }^{65}$, el "honesto médico maestro Rondibilis" citado por Rabelais, su formación básicamente médica (en la que descollaría por sus numerosas disecciones de cadáveres dado su condición de profesor de anatomía en Montpellier) no le impediría abordar el mundo de la ictiología, si bien limitándose en gran medida al mundo mediterráneo, participando de la misma prudencia que su compatriota, y rechazando expresamente los elementos que le parecían fabulosos y poco dignos de crédito. Por su parte, el italiano Hipólito Salviani (1514-1572) ${ }^{66}$, autor de una de las obras más bellas por sus ilustraciones jamás publicadas sobre los peces, no incluye en la misma elemento fantástico alguno.

La influencia de Olao Magno se dejará sentir, sin embargo, en la obra del celebérrimo cirujano francés Ambrosio Paré (1509-1590), que dedicará en sus Montres et prodiges ${ }^{67}$ un apartado a los monstruos marinos, en el que podemos encontrar, nuevamente, reminiscencias de Olao Magno, como revela la presencia del puerco marino ${ }^{68} \mathrm{o}$ de las ballenas ${ }^{69}$. No obstante nuestro autor introduce elementos nuevos que tendrán una cierta fortuna en la iconografía teratológica posterior, como la imagen de un monstruoso pez volador encontrado en las costas venecianas en $1550^{70}$, o la representación de una gigantesca ballena varada en la ribera del Escalda en $1577^{71}$.

\footnotetext{
64 BELON, Pierre, De aquatilibus, París, Carolum Stephanum, 1553, edición digital en la biblioteca de la Universidad de Estrasburgo http://imgbase-scd-ulp.u-strasbg.fr/displayimage.php?album=17\&pos=1 (30-10-2007). Sobre su figura, LETESSIER, Fernand, « Vie et survivance de Pierre Belon », Actes du Colloque Renaissance-Classique du Maine (Le Mans, 1971), pp. 107-128, 1975.

${ }_{65}$ RONDELET, Guillaume, Histoire entière des poissons, Lyon, Mace Bonhome, 1558, biblioteca de la Universidad de Estrasburgo http://imgbase-scd-ulp.u-strasbg.fr/displayimage.php?album=246\&pos=1 (30-10-2007).

66 SALVIANI, Hipólito, Aquatilium animalium historiae (Roma, 1557), edición digital en (http://alfama.sim.ucm.es/dioscorides/ consulta_libro.asp?ref=x53300285x)(30-10-2007), Biblioteca de la Universidad Complutense de Madrid.

67 Edición castellana en PARE, Ambroise, Monstruos y prodigios (1575), Madrid, Siruela, 2000.

68 PARE, Ambroise, Les oeuvres, p. 1070.

69 PARE, Ambroise, Les oeuvres, p. 1082.

70 PARE, Ambroise, Les oeuvres, p. 1077.

71 PARE, Ambroise, Les oeuvres, pp. 1082-1083.
} 
A lo largo del siglo XVII seguiremos encontrando referencias al respecto. Un ejemplo muy representativo viene proporcionado por el italiano Ulises Aldrovandi (1522-1605), médico y filósofo, profesor de historia natural en la Universidad de Bolonia, organizador de un jardín botánico y de una cámara de las maravillas, y que en 1594 firmará un contrato con el impresor veneciano Francesco de Franceschi para la publicación de una historia natural, aunque la enormidad de sus dimensiones provocó que muchos de sus tomos vieran la luz de forma póstuma, entre ellos el dedicado a ictiología ${ }^{72}$, suponiendo sus aportaciones un retroceso frente a los grandes ictiólogos del siglo XVI dado que, en realidad se trata de una historia literaria de los animales con una rudimentaria descripción zoológica, reuniendo cuanto fue escrito desde los puntos de vista más dispares, incluyendo mitología, prodigios y monstruosidades ${ }^{73}$. Volverá a tratar el tema en su obra Monstrorum historia ${ }^{74}$, obra con un apéndice titulado Paralipomenis Historiae Omnium Animalium de Bartolomeus Ambrosinus, profesor de la Universidad de Bolonia. Los ejemplos incluidos ya los hemos podido encontrar con anterioridad, incluso a nivel iconográfico, que el ilustrador copia literalmente: las serpientes marinas ${ }^{75}$, el $« c e t u s$ capillatus» ${ }^{76}$, el «apro cetaceo» ${ }^{77}$, el «ceto barbato» ${ }^{78}$, el puerco marino ${ }^{79}$, el fiseter ${ }^{80}$ y el rosmaro ${ }^{81}$ de Olao Magno, el pez volador ${ }^{82}$ de Ambroise Paré, y el monoceros marino de André Thevet ${ }^{83}$.

De una credulidad similar padece en algunas ocasiones el inglés John (o Johannes) Johnston (1603-1675), interesado por la medicina y por la historia natural, y que residiera durante gran parte de su vida entre Alemania y los Países Bajos, siendo autor de una de las últimas grandes enciclopedias de historia natural, que apenas aporta nada nuevo, puesto que repite casi sin variaciones el plan de Gesner y Aldrovandi repitiendo sus mismos errores y confusiones ${ }^{84}$, si bien ello no impide que sus láminas sean, en muchas ocasiones, de una gran belleza ${ }^{85}$, y en el que podemos encontrar representaciones, nada originales por otro lado, del pez volador ${ }^{86}$, el 4 ceto britannico» ${ }^{87}$ y el monoceros marino ${ }^{88}$.

Pero los monstruos marinos no se limitan al ámbito de peces y cetáceos, sino que nos ofrecen todo un elenco de seres antropomorfos que ya encontramos en las obras de los autores clásicos. En este sentido, tuvieron una gran trascendencia posterior las descripciones de tritones y nereidas incluidas por Plinio en su Historia natural ${ }^{89}$, a las cuales los autores renacentistas se referirán en más de una ocasión. El español Pero Mexía, por ejemplo, que citará la obra del escritor latino, indica cómo "Hay algunos peces que tienen forma y talle de hombres, y que entre ellos hay macho y hembra, y la hembra tiene la misma forma de mujer, a ellos llaman tritones, y a ellas nereidas...Teodoro Gaza...estando él en Grecia, en la costa de la mar, y habiendo pasado una muy grande tormenta y tempestad extraña, la mar echó en la costa alguna cantidad de peces, y entre ellos vio un pece o nereida de rostro perfectamente humano, de mujer muy hermosa, y así lo parecía hasta la cintura, y de ahí abajo fenecía en cola como de langosta, según vemos

72 ALDROVANDI, Ulises, De piscibus libri V. et de cetis lib. Unus (Bolonia, 1613), edición digital en la Biblioteca de la Universidad de Estrasburgo http://imgbase-scd-ulp.u-strasbg.fr/displayimage.php?album=265\&pos=0 (30-10-2007).

73 GUYENOT, Emile, y THEODORIDES, Jean, "Zoología", TATON, René, op. cit., p. 403.

74 ALDROVANDI, Ulises, Monstrorum historia, Bolonia, Hieronimus Tamburinus, 1642, edición digital en la Biblioteca de la Universidad de Estrasburgo . http://imgbase-scd-ulp.u-strasbg.fr/displayimage.php?album=256\&pos=3 (30-10-2007)

75 ALDROVANDI, Ulises, De piscibus, p. 344.

76 Paralipomenis Historiae Omnium Animalium, p. 99.

Paralipomenis, p. 63.

Paralipomenis, p. 101.

ALDROVANDI, Ulises, Monstrorum historia, p. 353.

Paralipomenis, p. 102.

Paralipomenis, p. 107.

ALDROVANDI, Ulises, De piscibus, p. 437.

ALDROVANDI, Ulises, De piscibus, p. 695.

4 GUYENOT, Emile, y THEODORIDES, Jean, op. cit., p. 405.

85 JOHNSTON, John, Historiae naturalis de piscibus et cetis libri V, Frankfurt, Math. Meriani, 1657, edición digital en la Bblioteca de la Universidad de Estrasburgo http://imgbase-scd-ulp.u-strasbg.fr/displayimage.php?album=584\&pos=0 (30-10-2007).

86 JOHNSTON, Johannes, Historiae naturalis, p. 36v.

87 JOHNSTON, Johannes, Historiae naturalis, p. 216v.

88 JOHNSTON, Johannes, Historiae naturalis, p. 218v.

89 ELIANO, Claudio, op. cit., XIII, 21, "El tritón de Tanagra", p. 21

90 MEXIA, Pero, Silva de varia lección, tomo I, edición de Antonio Castro, Madrid, Cátedra, 1989, cap. XXIV, "De los tritones y nereidas", pp. 374-375. 
pintada la que dice el pueblo sirena de la mar"90 . Guillaume Rondelet dedicará un capítulo a las Nereidas y aludirá al conocido episodio de Plinio ${ }^{91}$. Y las referencias podrían multiplicarse hasta el infinito: los tritones incluidos en las obras de Conrad Gessner ${ }^{92}$ o Ambroise Parée ${ }^{93}$, los monstruos marinos antropomorfos de Ulises Aldrovandi ${ }^{94} \mathrm{o}$ Johannes Johnston ${ }^{95} .$. y un sinfín de citas que podríamos extraer de autores de lo más variopinto, que incluso localizarán a estos seres en las regiones menos conocidas por los europeos.

Feijóo (1676-1764), por no citar más que un ejemplo, en su Teatro crítico universal se hará eco de estos hombres marinos, refiriéndose a un episodio "visto en Brest el año de 1725, y de que dan amplia noticia las Memorias de Trevoux del mismo año, Tom. IV, pag. 1902. Viéronle largo tiempo treinta y dos personas, que había en un bajel, cuyo Capitán era Olivier Morin. Era perfectamente proporcionado, y sus miembros en todo semejantes a los nuestros, salvo que entre dedos de manos, y pies tenía una especie de aletas al modo de las anades. Sería prolijidad referir los varios movimientos, y ademanes que hizo todo el tiempo que duró la observación. Lo más notable fue, que viendo la figura, que había en la proa del bajel, que era imagen de una mujer hermosa, después de contemplarla, suspenso un rato, se abalanzó fuera del agua, en ademán de querer asirla. Hubo también dos circunstancias ridículas en este suceso. La primera de parte del monstruo, el cual, como haciendo irrisión de la gente del navío, vueltas a ella las espaldas, y levantado algo en el agua, exoneró el vientre a vista de todos. La segunda, de parte del Contramaestre del bajel, el cual teniendo arbolado ya un arpón para tirarle, dejó de arrojarle, sorprendido de un terror pánico. Es el caso, que el año antecedente un Francés, llamado Lacommune, en el mismo bajel se había desesperadamente quitado la vida, y le habían arrojado al margen en el mismo sitio. Ocurrióle, pues, al Contramaestre al tiempo que estaba para lanzar el arpón, y se le imprimió fuertemente, que el hombre marino era no más que un espectro, fantasma, o aparición del desventurado Lacommune" 96.

Pero los ejemplos más delirantes, sin lugar a dudas, de estos seres antropomorfos, vendrán dados por el pez monje y el pez obispo. El primero de ellos fue hallado en la costa báltica danesa en la primera mitad del siglo XVI, y, según recogía en 1553 Kaspar Peucer (Commentarius de praecipuis divinationum generibus), llevaba una "coronae monachorum " y "vestita suo exprimebat monachum". El pez, de forma humana, mostraba la cabeza tonsurada al igual que los frailes, y el cuerpo estaba cubierto de escamas dispuestas en forma de cogulla religiosa ${ }^{97}$. Peucer no incorporaba iconografía alguna, pero su descripción gozó de una gran fortuna. Ya será incluido tres años más tarde en la obra de Pierre Belon ${ }^{98}$. Y se haría eco del mismo Conrad Lycosthenes ${ }^{99}$, que situará el hallazgo en 1546 en las cercanías de Copenhague, y lo describirá con un hábito de monje, aunque con la parte inferior en forma de pez, remitiéndose a la obra de Kaspar Peucer ${ }^{100}$, mostrándonos un segundo hallazgo realizado en 1549 en Haffnia, en la costa del mar Báltico ${ }^{101}$. Naturalmente, los autores posteriores recogerán estos testimonios, incluyendo en sus respectivas obras la iconografía de Belon: así, Conrad Gessner, si bien ubica su aparición en las costas de Noruega, que le debieron parecer más exóticas dado su conocimiento de la obra de Olao Magno ${ }^{102}$, Guillaume Rondelet (que vuelve a situarlo en Noruega) ${ }^{103}$, Ambroise Paré (que se remite al anterior) ${ }^{104}$ y Ulises Aldrovandi ${ }^{105}$. Todavía a finales del siglo XVII Antonio de Fuentelapeña (1628-1702), se referirá a este episodio, mostrando cómo "en la ribera de Noruega se cogió un pescado, que tenía el rostro de

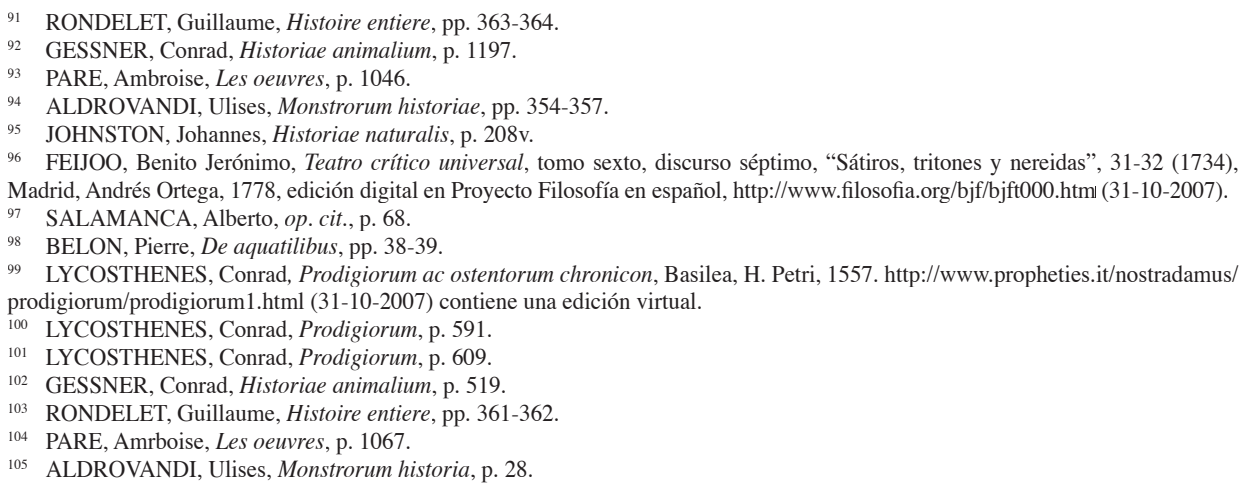


hombre, la cabeza lisa, y sin pelo, como raída a navaja, en los hombros tenía una cubierta a manera de capilla de fraile, y en lugar de brazos dos largas aletas, que parecían mangas, y la parte inferior se terminaba en una ancha cola, y en fin era todo él de tal forma, que en viéndole todos le llamaron fraile, y así quedó siempre con este nombre, por su semejanza, por la cual no se sabe otro nombre, que fraile"106, mostrando su conocimiento de la obra de Belon y Rondelet.

Idéntica transmisión acrítica tiene lugar en el caso del pez obispo. Se referirá a tan extraña criatura Guillaume Rondelet, indicando su hallazgo en las costas de Polonia en $1531^{107}$, y la noticia será transmitida por Conrad Gessner (que cita al primero) ${ }^{108}$, Ambroise Paré (que toma como autoridad a ambos) ${ }^{109}$, Ulises Aldrovandi ${ }^{110}$, y, nuevamente, por Fray Antonio de Fuentelapeña, nos revela cómo "En el mismo mar Báltico, junto a un lugar de la Noruega (nuevo cambio de ubicación geográfica) llamado Elepoca, el año de 1531 se cogió un pescado, que tenía forma de Obispo, con su mitra, roquete, y guantes, de tal suerte, que Mayolo le llama hombre marino, y dice de él, que representaba y semejaba totalmente un obispo con sus vestiduras episcopales. Este obispo se presentó a Segismundo, rey de Polonia, y no vivió más que tres días, según Mayolo, pero Gilberto romano, médico de Roma, que tuvo los retratos de este monstruo (o pescado obispo) y del pez fraile, afirmó, y dijo lo sabía de quien le dio los retratos, que como dicho pez obispo, con algunas señales pareciese significar, y dar a entender, que deseaba volver al mar, que le volvieron a él, y que al momento que vio sus aguas, le arrojó a ellas" ${ }^{111}$.

Producto de las regiones mediterráneas será el peje Nicolao. La versión italiana de la leyenda precede a la española, y se sitúa en la segunda mitad del siglo XV. Ya Alessandro Alessandri (14611523), en sus Dies geniales (1532) nos narra el "Miraculum de homine qui plus in mari quam in terris degebat, maximaque aequora velocissime tranabat", y una leyenda similar es recogida por Benedetto Varchi (1503-1565), aludiendo a "un siciliano humilde que no sólo nadaba entre 60 y 80 millas en el mar cuando estaba embravecido... sino que vivía más bajo el agua que en tierra, no creía que podría vivir y respirar sin cada día no iba al agua a perseguir peces del mar...llegando a estar dos o tres días bajo las olas antes de volver a tierra" 112 . Pero Mexía también transmite un relato parecido: "Desde que me sé acordar, siempre hoy contar a viejas no sé qué de cuentos y consejas de un pece Nicolao, que era hombre y andaba en la mar, y de él decían otras cosas muchas en este propósito...de lo que escriben dos hombres de mucha doctrina y verdad: el uno es Joviano Pontano (Giovanni Pontano, 1429-1503) varón doctísimo en letras de humanidad y singular poeta y orador, según sus libros lo testifican; y el otro, Alessandro

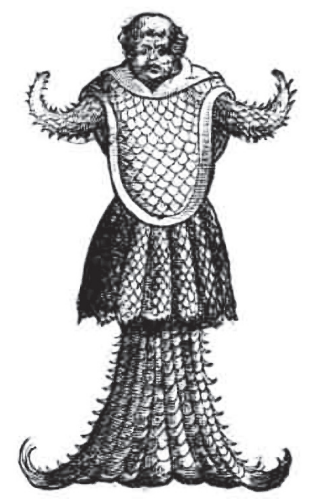

Conrad Gessner, El pez monje.

106 FUENTELAPEÑA, Antonio de, El ente dilucidado, p. 169.

107 RONDELET, Guillaume, Histoire entiere, pp. 362-363.

108 GESSNER, Conrad, Historiae animalium, p. 520

109 PARE, Ambroise, Les oeuvres, p. 1067.

110 ALDROVANDI, Ulises, Monstrorum historia, pp. 355 y 358.

111 FUENTELAPEÑA, Fray Antonio de, El ente dilucidado, p. 169.

112 SALAMANCA, Alberto, op. cit., p. 72. 


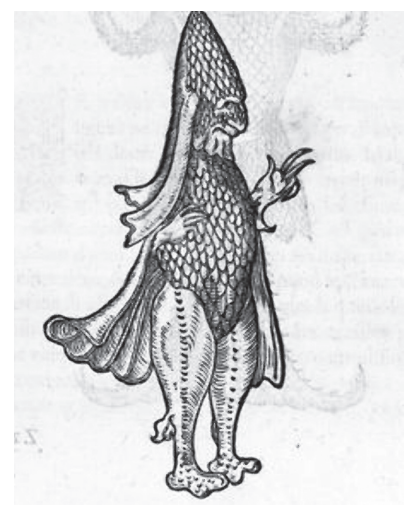

Guillaume Rondelet, El pez obispo.

de Alexandro, excelente jurisconsulto y muy docto también en humanas letras, el cual hizo un libro, llamado Días geniales, que contiene muy grandes antigüedades...Estos dos, pues, escriben que, en su tiempo, en Catánea (en el reino de Sicilia) fue un hombre a quien, por lo que se dirá, llamaban todos el pece Colán, el cual hombre, desde muy niño, tuvo tanta inclinación a andar en la mar nadando, que noches y días y en todo tiempo no era su descanso otra cosa. Y vino el negocio yendo de poco a mucho, a tanto extremo, que el día que no estaba lo más de él en agua, decía que sentía tanta pasión y pena, que no pensaba poder vivir, y como se hizo hombre en esta continuación, fue tan grande y tanta su habilidad y fuerza en el agua, que aunque hubiese grande tormenta en la mar, nadaba y andaba en ella sin temor ni peligro...y andando así lo topaban algunas naves, y él llamaba a los que iban en ellas y ellos lo acogían dentro, y preguntándose de sus caminos, le daban a comer y beber, y holgaba con ellos algún espacio, y luego saltaba en la mar y se iba su camino, y de esta manera muchas veces traía nuevas a los de tierra de los que topaba en la mar...créese que él se entró en alguna concavidad de las peñas de aquella mar que hay en el fondo de él, y fue tal, que no pudo salir y murió alli’’13.

Por lo que se refiere a España, las Relaciones de sucesos se hicieron eco de algunos casos parecidos. En 1608 se imprimió una relación en Barcelona en la imprenta de Sebastián de Cormellas, según la cual nuestro hombre pez nació en Rota y se crió como un niño normal pero a los diez años sólo quería bañarse y conocer el mar, su padre lo maldijo deseando que se quedara para siempre en el mar y que muriese si del agua salía, por lo que quedó convertido en un pescado la mitad del cuerpo, se sumergió y sólo volvía a tierra para ver a sus padres ${ }^{114}$. Pero el relato más completo será el proporcionado por Feijóo en relación al hombre pez de Liérganes, Francisco de la Vega Casar, episodio que tuvo lugar en $1679^{115}$.

A lo largo del siglo XVIII se asientan definitivamente los fundamentos de la zoología científica, con la clasificación sistemática de Carl von Linneo (1697-1778) en su Systema Naturae (primera edición, 1735), y la magna obra recopilatoria de Georges Louis Leclerc, conde de Buffon (1707-1788) Histoire naturelle, générale et particulière (1749-1788) ${ }^{116}$ A primera vista, el ambiente intelectual ya no era propicio para las referencias a los monstruos marinos, pero, curiosamente, en las postrimerías de la Ilustración va a nacer una nueva criatura. Aunque nunca se menciona en las sagas medievales noruegas, en el siglo XVIII Linneo incluirá al kraken entre los cefalópodos, si bien sin otorgarle ningún carácter monstruoso ni destructivo especial. Pero el obispo de Bergen Erik Pontoppidan

\footnotetext{
${ }_{113}$ MEXIA, Pero de, Silva de varia lección, cap. XXIII, "Del admirable nadar de un hombre, de do parece que tuvo origen la fábula, que el pueblo cuenta, del pece Nicolao", pp. 369-371.

114 SALAMANCA, Alberto, op. cit., p. 73.

115 FEIJOO, Benito Jerónimo, Teatro crítico universal, tomo sexto, discurso octavo, "Examen filosófico de un peregrino suceso de estos tiempos", 5-15 (1734), Madrid, Andrés Ortega, 1778.

116 Las obras de Buffon, en "Buffon et l'histoire naturelle: l' edition en ligne". Sobre sus valiosísimas ilustraciones, HOQUET, Thyerri, Bufón illustré: les gravures de l' Histoire naturelle (1749-1767), París, Museum nacional d’Histoire naturelle, 2007.
} 
(1698-1764), en su Historia natural de Noruega (Copenhague, 1752-1753), lo describirá como un animal del tamaño de una isla flotante, constituyendo un gran peligro para los marineros no por sí mismo, sino por el inmenso remolino que forma al descender hacia las profundidades marinas, aunque era muy capaz de sumergir un barco en el fondo del océano. El discípulo de Buffon Pierre Denys-Montfort (1766-1820), en su L' histoire naturelle generale et particuliere des mollusques (6 vols., París, 1801-1802), publicada como continuación de la obra de su maestro, se hará eco de estos relatos, mostrando al kraken como al animal más inmenso de nuestro planeta, insistiendo en su formidable agresividad ${ }^{117}$. Armand Landrin, en su obra Les monstres marins (consultada la edición publicada en París en 1870, aunque hay otras anteriores) ${ }^{118}$, recogerá una imagen de un calamar gigante, que debió inspirar, junto con las alusiones de Montfort, el archiconocidísimo episodio incluido en la obra de Julio Verne Veinte mil leguas de viaje submarino (1869).

Pero ya los monstruos marinos han quedado reducidos al reino de la literatura y lo fantástico. En una enciclopedia para niños publicada en España en la década de 1920, Tesoro de la juventud, se muestra, no sin un cierto desprecio, cómo "hasta los niños pequeños se burlan y ríen al presente de estas historias ridículas que aterrorizaron un día las mentes de los hombres cultos y de los filósofos de la antigüedad... lo que mueve a risa y asombro es que escribiesen libros serios en los que se relataban terribles aventuras habidas con estos seres imaginarios" ${ }^{\prime 119}$ )...y, para ilustrar, se incluyen imágenes extraídas de los venerables grabados de Gessner y Aldrovandi. El mito, finalmente, ha acabado convirtiéndose en un mero relato infantil, aunque seguirá conservando una vertiente relacionada con el Otro absolutamente devastador, siendo ejemplo de ello el Moby Dick (1851) del novelista norteamericano Herman Melville (1819-1891)...o el celebérrimo Tiburón (1975) de Steven Spielberg.

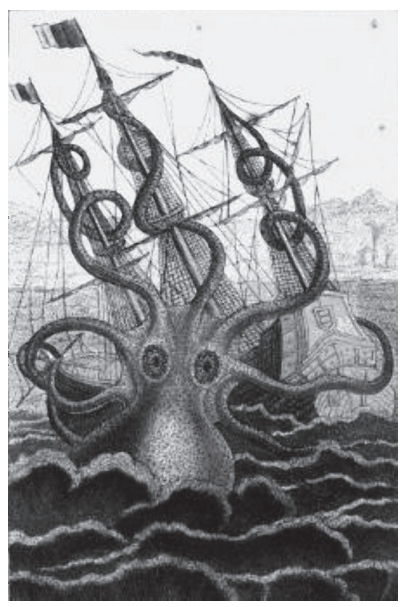

Pierre Denys de Montfort, El kraken.

117 DELUMEAU, Jean, op. cit., p. 67.

118 Edición digital en la Bibliotheque Nationale de France.

119 Tesoro de la juventud, s.l., s.a., tomo 17, p. 5954. 